the grounds for treatment do not depend primarily on the diagnosis. The line of argument in the Grigorenko report shows that the decisive issue is whether an aocused person possesses the necessary critical faculties and self-oontrol for his opinions and actions or whether, owing to certain psychiatric abnormalities, this is not the case. Hence differences of opinion over the diagnostic limits of a schizophrenic illness are not of critical importance.

(2) In the Grigorenko report the term "paranoid development" and "delusional ideas" are used where German-trained psychiatrists would use, at most, the term "over-valued ideas" (überwertige Ideen) (Wernicke). These are ideas that are comprehensible in the context of a person's life or the historical circumstances in which he lives and which are maintained with strong emotion and persistence even against considerable opposition in the surrounding world. From a strictly psychiatric standpoint, however, it is not possible to distinguish between these so-called over-valued ideas and moral and religious beliefs maintained with persistence and strong affective colouring. They are dependent on the philosophical or political system of values which determine the assessment of such ideas.

(3) Strongly held beliefs and ideas, and the actions resulting from them, do not as such determine responsibility, since they have been based on comprehensive grounds and held with normal conviction. There are, of course, exceptions in which such comprehensible ideas arise from a clearly discernible illness, mostly schizophrenia, but these would have to be determined in each case separately. In the case of Grigorenko, as in other cases known in the West that may be less well documented, the "reformist ideas" cited do not impress as manifestations of a mental illness. They correspond to a widely held humanist and liberal tradition which, though not officially recognized in the Soviet Union, is surely well known there from historical experience and from relations with foreign countries. The views held by Grigorenko and likeminded people contain nothing which in themselves can be considered absurd, bizarre, or egocentric as would be the case, for instance, in a paranoid schizophrenic delusion. In the documents that have reached the West it is striking that the forensic diagnosis of psychiatric disturbances rests overwhelmingly on such "reformist ideas." Yet such ideas cannot be used as proof of a mental disturbance with however much determination and feeling they may be expressed.

(4) Criticism of psyohiatric reports on dissenters made in the Serbsky and other Soviet institutes rests less on the diagnostic category ascribed to each case-about which there may be disagreement-than on the arbitrary way in which the expression of such "reformist ideas" is equated with lack of critical faculties, responsibility, and self-control. Such reasoning is considered by the German school of psychiatry, as well as by all other schools, to be inadmissible because it supposes pathological disturbances of the intellect and behaviour which are not in themselves disturbed at the time of the incriminating act. This impression is particularly striking if one studies the documents ${ }^{1}$ more closely and analyses the reasoning behind them. Such an analysis forces one to suspect that assessments are not made on scientific and clinical grounds but are based on political and opportunist considerations. (5) The impression of poverty of psychiatric evidence cannot be erased by the proceedings at the conference at the Serbsky Institute in October 1973. This impression is strengthened after thorough study of the Bukovsky papers, ${ }^{1}$ which are now available in English, French, and German. The genuineness of these documents has never been questioned. Bukovsky, who for his courageous act was sentenced to a long term of imprisonment, has thus become a martyr to psychiatry for protesting, at the risk of his life and liberty, against these misuses. The same can probably be said of the Jewish Ukrainian psychiatrist Dr. Gluzman, who dared to subject the Serbsky Institute's psychiatric report on Grigorenko to criticism-whatever may have been said at the Serbsky Institute about the nonexistence of a psychiatrist of this name. It is not only to justify and pay homage to these courageous men but also to prevent further misuse of forensic Dsychiatry that psychiatris:s and their organizations in all coun ries should unite as never before to raise critical and accusing voices of warning more strongly and loudly than hitherto. No psychiatrist who has carefully and objectively studied the Bukovsky documents can fail to do this, either personally or through his professional organization.-I am, etc.,

University Psychiatric Clinic,

WALTER VON BAEYER Geidelberg

1 Committee on the Judiciary, U.S. Senate, Abuse of Psychiatry for Political Repression in the
Soviet Union. Washington, D.C., U.S. GovernSoviet Union. Wash
ment Printer, 1972.

Distribution and Supervision of Oral Contraceptives

SIR,-Dr. M. V. Smith and his distinguished cosignatories (19 October, p. 161) present a powerful consensus in favour of widening the range of those empowered to dispense oral contraceptives. While not questioning the need for some liberalization, I am unhappy about the extent of their proposal.

Like myself, many who work in the field of family planning believe that much can with benefit be delegated to the nursing members of the team, including the dispensing of resupply oral contraceptive packs. We do not all share the view that fitness and suitability for this method can be decided by other than a doctor, and preferably the family practitioner. Nor will the latter lightly abandon the advantages to the total care of their patients of periodic consultation and examination.

We are aware that there are those who would go even further than your correspondents-those who advocate the open sale of oral contraceptives across the counter, who would have technicians trained to insert intrauterine devices and even to perform vasectomy, and who decry the role of doctors in contraception. Unfortunately, their thesis is indirectly supported by those who for a variety of reasons regard family planning as outside the scope of normal medical practice.

One hopes that any decision to modify current regulations will be based upon a consideration of the balance of risks and benefits to our patients and upon a determination not to sacrifice standards of medical care and the doctor-patient relationship to political or financial expediency. Should it be decided to extend to nondoctor health personnel the right to dispense oral contraceptives under the supervision of a doctor, the responsibilities of the doctor and the role of the health personnel must be governed by a code of practice similar to that which governs the practice of midwives.-I am, etc.,

Fleet, Hants

NORMAN TALBOT

\section{First-aid Treatment of Poisoning and} Cardiac Arrest

SIR,-At a recent meeting we discussed the letters on "Danger of Saline Emetics in First Aid for Poisoning" from Drs. C. J. C. Roberts and M. J. Noakes (14 September, p. 683) and from Drs. $M$. Winter and D. J. E. Taylor (28 September, p. 801). On the evidence which has been presented to us it was decided that emesis contributes little to the first-aid treatment of poisoning. We therefore propose to recommend that at the next impression of our joint manual (third edition) the instruction to produce vcmiting should be omitted.

We are also recommending the omission of the instruction to thamp the chest repeatedly in cases of cardiac arrest because of the accumulating evidence that repeated "chest thumping" is of value only under hospital conditions. External cardiac compression should still be practised as recommended.-We are, etc.,

ANDREw RAFFLE
Chief Medical Officer,

H. R. F. MACDONALD Chief Medical Officer,
St. Andrew's Ambulance Association JOHN GRAY Chief Medical Officer,

\section{Two-phase Blood Culture System}

SIR,-In many developing countries where salmonellosis, brucellosis, and meningococcal disease are endemic oommercial blood culture systems are not readily available and preparation of similar systems requires equipment for carbon dioxide gassing not normally found in small hospital or field laboratories. Ox bile is excellent for isolation of salmonella, easy to prepare, and difficult to contaminate, but it is ineffective for isolating more fastidious species.

We have used a two-phase Castaneda bottle ${ }^{1}$ for routine blood culture. This system (TSA/Thio), which can be prepared in any laboratory equipped with an autoclave or pressure cooker, consists of a 4-oz $(113 \mathrm{~g})$ prescription bottle containing $30 \mathrm{ml}$ of trypticase soy agar (BBL) and $30 \mathrm{ml}$ of thioglycolate medium 135-C (BBL) with $1 \%$ sodium citrate as an anticoagulant. TSA/ Thio has the additional advantage of not requiring subculture to identify positive cultures since growth in the bottle is usually manifested by colony formation on the agar slant surface. The data in the table show that TSA/Thio is as effective in isolating salmonella, brucella, and meningococci as a 
Efficiency of TSA/Thio as a Culture Medium compared with TSA/TSB and Ox Bile

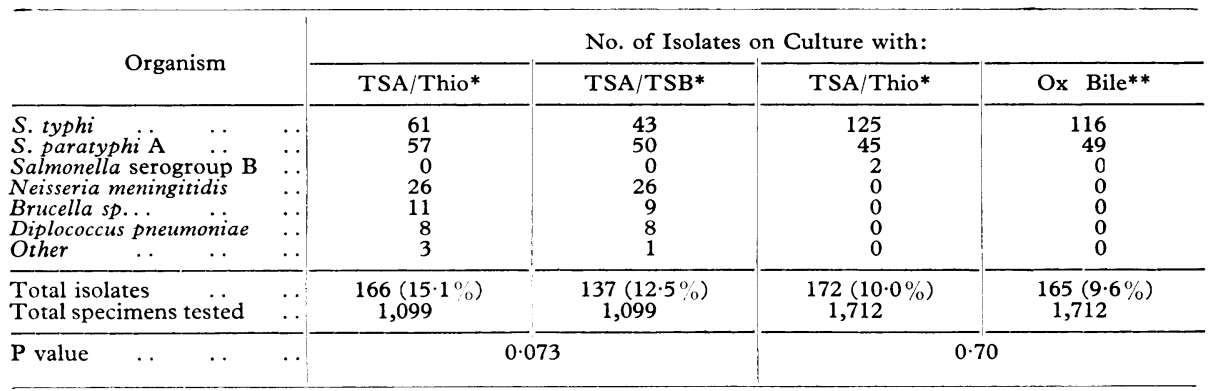

*Inoculated with $5 \mathrm{ml}$ of patient's blood. Incubated for up to 14 days.

**10 $\mathrm{ml}$ of ox bile inoculate with $3 \mathrm{ml}$ of patient's blood. Subcultured on Trypticase soy agar plates on days 1, 3 and 7 .

similar system (TSA/TSB) that was composed of trypticase soy agar and trypticase soy broth (BBL) with Grobax (sodium polyanethol sulphonate; Roch Diagnostics) and antibiotic inhibitors and which was gassed with a mixture of $5 \%$ carbon dioxide and $95 \%$ air. $^{2}$ TSA/Thio was also found to be as efficient as ox bile $(10 \%)$ in the isolation of salmonella.

We have diagnosed 272 cases of typhoid and paratyphoid fever, 14 of brucellosis, and 30 of meningococcaemia by culture with TSA/Thio during the past year. We think it is an excellent system for routine blood culture in areas endemic for these diseases. -We are, etc.

J. E. SIPPEL U.S. Naval Medical Research Unit No. 3 , Cairo, Egypt

ABDulla S. Diab

The University of Alexandria,

A. Ellakani

Alexandria, Egypt

1 Castaneda, M. R., Proceedings of the Society for Experimental Biology and Medicine, 1947, 64, 2 Sanborn, W. R., and Dyer, J. C., Fournal of the Egyptian Public Health Association, 1970, 45,

\section{Place of Diagnostic Radiology in Medicine}

Sir,-Like Dr. A. S. Bligh (14 September, p. 684), I am disappointed with the lack of correspondence following the article by Dr. J. W. D. Bull on the place of diagnostic radiology in medicine (10 August, p. 394). The serious situation he discussed is known to radiologists throughout the country. Repeatedly one hears of difficulties in obtaining equipment and problems with outof-date $x$-ray departments, much bigger work loads, and fewer staff. It has been shown in Scandinavia and, more recently, in the United States that radiology holds a prior position in diagnostic services. Our administrative and medical colleagues in the National Health Service have failed to give it financial priority.

Like Dr. Bull, I believe that the difficulty in promoting postgraduate interest in radiology partly results from our failure to establish a satisfactory programme for teaching it to undergraduates. There is a place for using our radiological training in both the preclinical and clinical years. Radiologists should take part in teaching anatomy, physiology, and pathology as well as clinical subjects, and in postgraduate education radiology has a place in almost all specialties. A satisfactory teaching programme will require more teachers as well as upgraded departments. Plans to establish chairs in radiology should be actively supported by deans of medical schools and by all radiologists and their medical and surgical colleagues. To postpone action will perpetuate a radiological service that is inferior to that in Europe and the United States.

There is now a serious "radiological drain" to other countries. This must be checked and recruitment into the specialty increased. Academic departments, by undergraduate and postgraduate teaching and by their interest in research, would hopefully stimulate a new interest among young doctors in radiology as a career. An enthusiastic, sustained, and vociferous effort is needed from all who are interested in our subject.-I am, etc.

St. Mary's Hospital,

OSCAR CRAIG

\section{Comparison between Free Thyroxine Index} and Effective Thyroxine Ratio

SIR,-Like Dr. E. G. M. D'Haene and others (21 September, p. 708) we too are interested in the relationship between effec- tive thyroxine ratio (E.T.R.) and free thyroxine index (F.T.I.). Despite the literature referred to by the authors we suggest the approach to the determination of the E.T.R./F.T.I. relationship should be as follows.

The E.T.R. reflects serum thyroxine (T-4) levels and automatically compensates to a large extent for variations in thyroxinebinding globulin (T.B.G.) capacity. ${ }^{1}$ If T.B.G. concentration showed no variation in the normal population, then the value for the E.T.R. would be determined entirely by the level of T-4. For this reason there is a very high linear correlation between E.T.R. and T-4 when patients with T.B.G. abnormalities are excluded.

In a recent study we measured $\mathrm{T}-4$ using Thyopac 5 and absolute free thyroxine concentration (A.F.T-4), by the method of Sterling and Brenner ${ }^{2}$ in 180 consecutive patients who were not suspected of having T.B.G. abnormalities. The results (fig. 1) show clearly that T-4 and A.F.T-4 are not linearly related. E.T.R. values were also obtained in these patients and as expected the E.T.R./A.F.T-4 correlation was also non-linear. This conflicts with the findings of Wellby et al., ${ }^{3}$ but is in agreement with the findings of Mincey et al. ${ }^{4}$ The problem is understandable if one considers what happens to the value of A.F.T-4 when T-4 is added to serum in vitro. As the binding sites approach saturation a given increment of T-4 produces a relatively greater increment in A.F.T-4. Examination of the law of mass action led us to plot $1 / \mathrm{T}-4$ against 1/A.F.T-4 in order to obtain a linear correlation between these two parameters. The result is shown in fig. 2 .

If we accept the findings of Wellby et al. ${ }^{3}$ that A.F.T-4 is linearly related to F.T.I., then since E.T.R. is not linearly related to A.F.T-4, E.T.R. cannot be linearly related to F.T.I. We are therefore not surprised at the finding of Dr. D'Haene and his colleages. It would be interesting to know if by plotting 1/E.T.R. against 1/F.T.I. the authors obtain a higher linear correlation than they have obtained at present.-We are, etc.,

A. M. B. Boss

D. KINGSTONE

Endocrine Unit,

New End Hospital,
London N.W.3

1 Thorson, S. C., et al., British Medical fournal, $1972,2,67$.

2 Sterling, K., and Brenner, M. A., Fournal of Clinical Investigation, 1966, 45, 153.

Wellby, M. L., O'Halloran, M. W. and Marshall, J., Clinica Chimica Acta, 1973, 45, 255.

Mincey, E. K., et al., fournal of Nuclear
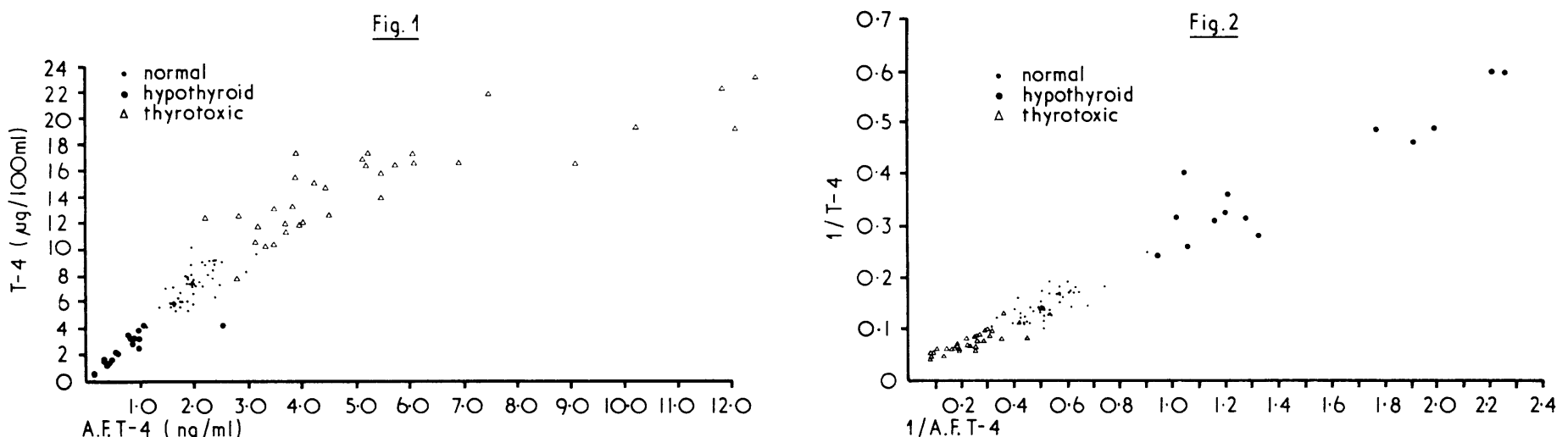